\title{
Material windows and working stations. The discourse networks behind skeuomorphic interface in Pathfinder: Kingmaker
}

Images

vol. XXIX/no. 38

Poznań 2021

ISSN $1731-450 \mathrm{X}$

\begin{abstract}
Michał Dawid, Material windows and working stations. The discourse networks behind skeuomorphic interface in Pathfinder: Kingmaker. "Images” vol. XXIX, no. 38. Poznań 2021. Adam Mickiewicz University Press. Pp. 73-94. ISSN 1731-450X. DOI 10.14746/i.2021.38.05.

The article probes the intermedial structure of the skeuomorphic interface in Pathfinder: Kingmaker. The author indicates that intermedia research in game studies is often diachronically limited, focusing on material and semiotic interactions between "old" and "new" media. He proposes to open the field onto historically aware discoursive analysis and bases his method on Friedrich Kittler's notion of "discourse networks". This allows him to inspect the game in relation to technologically-founded networks that embody or bring into life specific modes of though and experience. During his analysis, he discovers that the interface design is involved with navigation devices in Late Medieval and Early Renaissance periods, Alberti's windows as objects through with narrative spaces become visible, isometric modes of objective thinking, industrial and cybernetic notions of control, and the Xerox invention of the computer as a working environment.
\end{abstract}

KEYWORDS: discourse networks, intermediality, graphical user interface, media archeology, digital games

The investigation of media and their structures has always been involved with the phenomenon of intermediality. After all, the relations and interactions between various media practices expose their qualities. No matter if strategically designed or not, intermediality becomes a key phenomenon that defines what a given medium is. That is why André Gaudreault and Philippe Marion simply announce: "A good understanding of a medium [...] entails understanding its relationship to other media." [1]

Because intermediality plays such a tremendous role in media studies, it is not surprising that there is a growing body of work that deals with digital games and their connections with other forms of communication. This research includes a wide range of topics: the authentication of historical games through well-known modes of historical narration[2]; how artistic games transform the literary media

[1] A. Gaudreault, P. Marion, The Cinema as a model for the genealogy of media, "Convergence" 2002, vol. 8 , no. 4, p. 15. The importance of intermedial research is elaborated on in: I.O. Rajewsky, Intermediality, intertextuality, and remediation: a literary perspective on intermediality, "Intermédialités" 2005, vol. 6, no. 6, pp. 48-49, DOI: 10.7202/1005505.

[2] T. Raupach, Towards an analysis of strategies of authenticity production in World War II first-person shooter games, [in:] Early Modernity and Video 
by integrating them into their structures [3]; the combination of static comics with digital game media;[4] and games' dependance on cinematic modes of representation,[5] among others. [6]

Much of such research attempts to inspect intermediality to find out how games adapt or reconfigure pre-digital forms. In turn, the intermedial perspective on games tends to focus on the material, aesthetic, and semiotic qualities of chosen products, overlooking the intricacies of historical and cultural aspects of media. To scrutinize the characteristics of games, researchers tend to treat both digital games and pre-digital media as fixed classes of established forms, [7] almost always regarding them as singular phenomena (film, literature, photography...).

I try to overcome this research inclination, which (as I am going to briefly show) is a consequence of the intermedial methodology and the distinction between "old" and "new" media. I propose to look at intermediality in games as a phenomenon encompassing both material and discoursive facets. I do not introduce a new typology (there are many to choose from already), but instead discuss how intermedial research of games can be enriched with Friedrich Kittler's theoretical model of "discourse networks". I implement this method to probe the skeuomorphic graphical user interface of Pathfinder: Kingmaker.

Many media researchers agree that interfaces are an important topic of study, often regarding them as a vital component of digitally mediated experiences.[8] Despite the variety of tackled topics, game studies still lacks a detailed historical examination of skeuomorphic interfaces. Such interfaces are common in games because, Piotr Kubiński explains, they support the immediate and immersive experiences. [9] This effect is possible thanks to the intermedial nature of skeuomorphism. The design practice represents digital processes by making the interface resemble other (usually older) media or objects. Graphical user interfaces are semiotic devices, thanks to which the inaccessible

Games, ed. T. Winnerling, F. Kerschbaumer, Newcastle 2014, pp. 123-138.

[3] A. Ensslin, Literary Gaming, Cambridge - London 2004 .

[4] A. Lippitz, Lost in the static?: Comics in video games, [in:] Intermedia Games - Games Inter Media: Video Games and Intermediality, ed. M. Fuchs, J. Thoss. New York 2019.

[5] I. Girina, Video game mise-en-scene remediation of cinematic codes in video games, [in:] Interactive Storytelling. ICIDS 2013. Lecture Notes in Computer Science, ed. H. Koenitz, T.I. Sezen, G. Ferri, Cham 2013.

[6] Ida Kathrine Hammeleff Jørgensen suggests that the intermedial research in game studies is still overshadowed by the transmedial method though: I.K.H. Jørgensen, Media and games: an intermedial framework, in
FDG '18: Proceedings of the 13th International Conference on the Foundations of Digital Game, ed. S. Dahlskog, S. Deterding, J. Font, Malmö 2018, <https://doi. org/10.1145/3235765.3235794>, accessed: 23.01.2021. [7] For examples see abstracts of: P. Groppo, Narrative ludology: intermediality in adventure games, "Em Tese" 2012, vol. 18, no. 3, DOI: 18. 96. 10.17851/19820739.18.3.96-108; Intermedia Games - Games Inter Media...; A. Enslin, op.cit.

[8] P. Celiński, Interfejsy. Cyfrowe technologie w komunikowaniu, Wrocław 2010, pp. 64-80; L. Manovich, The Language of New Media, Cambridge - London 2011, pp. 62-115; C.U. Andersen, S.B. Pold Interface Criticism, Aarhus N 2011, pp. 8-13.

[9] P. Kubiński, Gry wideo. Zarys poetyki, Kraków 2016, pp. 219-228. 
computer systems become understandable. I focus on Pathfinder because it carries out many foundational discourses about skeuomorphic design practices in game. The game's interface design fits within the scope of intermediality, which, as explained by Iryna O. Rajewsky and Jens Schröter, includes instances of media "re-representation" or "remediation," [10] in which "One medium refers to another and thereby it can comment on the represented medium." [11]

At its core, the research of intermediality is either concerned with the material interactions between distinct media forms or with historical transformations of media; [12] how media borrow from and influence each other, how one medium adapts the qualities of a different medium, and how new media distinguish themselves from previous forms of communications. Juergen E. Mueller scrutinized this fixation of the field, noting that it often excludes questions of "social and historical meanings and functions", focusing on the materiality of media instead. As a solution to the problem, he suggests researchers take into consideration the social meaning-making processes that are embedded in the materiality of (inter)media.[13] Such an approach could result in to use his words - an "intermedia-oriented cultural history of digital media and their social functions." [14] Unfortunately, Mueller offers only direction, not the tools needed for its implementation.

The historical perspective on intermediality often focuses on the processes of media emergences and evolutions, and also on the ontological and material foundations of (inter)media practices. Such an approach is interested in the construction of media history. André Gaudreault and Philippe Marion, for example, inspect how media are "born" and find their "identity" through intermedial relations. [15] The authors of the articles in Intermediality and Media Change[16] use the method to write about historical succession of media. Game researcher Aki Järvinen organizes “a continuum” of audio-visual styles adapted by digital games between 1970 s and 1990s. [17]

The research on intermediality in games is often limited to a topic of "games and..." other media. Britta Neitzel reports, for example, that: Videogames are not thinkable anymore outside of relation to literary themes, to (simple) structures of narration (interactive storytelling)

[10] I.O. Rajewsky, op.cit., p. 6o; J. Schröter, Discourses and models of intermediality, "CLCWeb: Comparative Literature and Culture" 2011, vol. 13, p. 4, DOI: 10.7771/1481-4374.1790.

[11] J. Schröter, op.cit., p. 5.

[12] I.O. Rajewsky, op.cit., pp. 46-57.

[13] J. Mueller, Intermediality, Quo Vadis A brief inventory and a road map for six central future research axes, "International Journal of Semiotics and Visual Rhetoric" 2019, vol. 3, p. 20, DOI: 10.4018/ IJSVR.2019070102.
The problem with intermediality
[14] Ibidem, p. 28.

[15] A. Gaudreault, P. Marion, op.cit.

[16] Intermedialityand media change, eds. J. Herkman, T. Hujanen, P. Oinonen, Tampere 2012.

[17] A. Järvinen, Gran Stylissimo: The audiovisual elements and styles in computer and video games, [in:] Proceedings of Computer Games and Digital Cultures Conference, ed. F. Mäyrä. Tampere 2002. 
or transformations of classical narrative patterns, to themes, visual patterns ("virtual camera") or methods of the production of films, references to painting, or musical dramaturgy." [18]

As a result, the historiography of media seen through the lens of intermediality risks becoming a history of so-called "old" and "new" forms of communication. While this division has certainly proven to be productive in many areas of research (including game studies), it reduces the historical process to an interaction between only two opposing categories: the analog past and the digital present. Pre-computer media are treated as an almost homogenous group of practices. Their history is rewritten from the perspective of the emerging computer. The rich and complicated past becomes constrained and simplified for the sake of the present. The computer is seen - I use Lev Manovich's influential words here - as "a set of different media and a system for generating new media tools and new types of media." [19] Thus, intermediality becomes a strategy for creating digital forms: "to represent the world or our experience in a new way" or to introduce "new ways of navigation and interaction with already existing media formats." [20] Many game scholars have been influenced by such a research philosophy, myself included.[21]

\section{A method}

The focus on the newness of the digital has been already questioned by the practitioners of "media archeology". Researchers within that field conceptualize media history as a non-linear phenomenon. As Siegfrid Zielinski strongly asserted, "The history of the media is not the product of a predictable and necessary advance from primitive to complex apparatus." [22] Media archeology then, Wolfgang Erst elaborates, opposes history, and "refers to what is actually there: what has remained from the past in the present like archaeological layers, operatively embedded in technologies." [23]

Media archeologists developed many concurrent methodologies that tackle the problem at hand, many of which treat past and present media as equal categories. For example, instead of writing about the progression of media, Jussi Parikka opts to look at transpositions that take place between different technological (and biological) systems.[24] Angela Ndalianis looks at how past media logic impresses and infuses

[18] B. Neitzel, Performing games: intermediality and videogames, [in:] Handbook of Intermediality, ed. G. Rippl, Berlin - Boston 2015, e-book.

[19] L. Manovich, Software Takes Command, New York - London 2013, p. 102.

[20] Ibidem, p. 196.

[21] See the research examples mentioned in the second paragraph.

[22] S. Zielinski, Deep Time of the Media: Toward an archaeology of hearing and seeing by technical means, trans. G. Custance, Cambridge - London 2006, p. 7.
[23] W. Ernst, Media Archaeography. Method and machine versus history and narrative of media, [in:] Media Archeology. Approaches, applications, and implications, ed. E. Huhtamo and J. Parikka, Berkeley, Los Angeles - London 2011, p. 241.

[24] J. Parikka, Insect Media. An archaeology of animals and technology, Minneapolis - London 2010, p. XIII. 
recent creations. [25] Erkii Huhtamo brings chosen aspects of the past and present media into conversation with each other.[26] Transposition, infusion, conversation, traces... Many of the terms used by media archeologists are also commonly used in intermedial research, suggesting that the field deals not only with history, but also with intermedial relations (even if it is often not framed as such). The goal of media archeology is to uncover the linkages between the variety of media forms (be it past or present).

In my approach, I combine the two methods, because the narrow understanding of history in intermediality can be solved by the non-linear direction proposed in media archeology. I argue that intermediality links digital games with distinct moments from the past or present. That is why it is necessary to see the referenced media as concrete phenomena with their own history. There is no unified literature or cinema, but rather complicated systems of devices that changes based on the technical, cultural, discoursive, and social developments. When games intermedially connect with those systems, they do not just represent the visual and semiotic qualities of given media, but become involved with their discoursive facets as well. As a consequence, the way a game is designed also becomes involved with chosen discourses.

In my understanding of discourses, I follow Michel Foucault, who saw them as systems of rules that define and govern socio-cultural domains, modes of enunciation, knowledge production, and perimeters of thinking.[27] To fully grasp the scope of the phenomenon in question, I propose to look at intermediality in games from an angle that was initiated by Friedrich Kittler. Kittler's research established that media technologies occur and act within "discourse networks" - webs of "power, technologies, signifying marks, and bodies" [28] that "allow a given culture to select, store, and process relevant data." [29] What is more, discourse networks are historically conditioned; they function in certain historical moments and change over time.

When using the term, Kittler tries to attune Foucault's method of discourse analysis to the cultural role of media. By doing so, he corrects Foucault's major oversight. There is no discourse without media.[30] Kittler emphasizes that technologies are shaped by different discourses, and at the same time develop or carry them out. In other words, the forms and functions of media embody or bring into life specific cultural rules. Therefore, technologically-founded networks shape human sub-

[25] A. Ndaliains, Neo-Baroque Aesthetics and Contemporary Entertainment, Cambridge - London 2004, p. 5 .

[26] E. Huhtamo, Dismantling the fairy engine. Media archeology as topos study, [in:] Media Archeology. Approaches..., p. 28.

[27] M. Foucault, The Archeology of Knowledge, transl. A.M. Sheridan Smith, New York 1972.
[28] D.E. Wellbery, Foreword, [in:] F. Kittler, Discourse Networks 1800/1900, transl. M. Metteer, C. Cullens, Stanford 1990, p. xiii.

[29] F. Kittler, Discourse Networks..., p. 369.

[30] Idem, Gramophone, Film, Typewriter, transl.

G. Winthrop-Young, M. Wutz, Stanford 1999, xli.

[31] Ibidem, p. $\mathrm{x}$-xli. 
jectivity by designating "schematism of perceptibility" [31] - epistemic formations and their limits. The technical limitations and affordances of media produce concrete ways in which things can be experienced.

There are two reasons as to why I chose the theory in question. Firstly, Kittler's works have influenced the field of media archeology. Parikka emphasizes that the field was born out of Kittler's "emphasis on the importance of the technical as a system of inscription, in the manner Foucault talked about, which related to both archaeological (conditions of knowledge) and genealogical (history is inscribed in various bodies, or materials) theories." [32] Secondly, and more importantly, the notion of discourse network can be easily relocated into the research of intermediality. The relationships between media become the relationships between the discourse networks those media represent. Such change enriches the outlook on intermediality, because it stops being seen as just a relation between two distinct categories of media (e.g. literature and cinema), becoming a much richer relationship between past and present discourses.

The analysis of intermediality in games should take into account that games reference or represent devices that were (or are) a part of a given discourse network. Consequently, games are not only related to the devices in question, but also to the discourse networks and the discourses they embody. When used in that way, an intermedial inspection should be able to reveal how those discourses produce gaming forms and specific modes of experience.

Such an examination is not interested in writing a history of digital games. Rather, it follows the media archeological approach, which is "about rereading and rewriting epistemological (rather than simply temporal) momenta." [33] Still, it is impossible to fully grasp the scope of a discourse network and its innerworkings. That is why I follow Kittler's advice[34] and during my analysis provide "snapshots" of moments which contributed to the development of Pathfinder's interface. I treat the chosen game as an excavation site, from which I can dig up evidences of different discourse networks.[35]

\section{Pathfinding}

Pathfinder: Kingmaker is a computer roleplaying game inspired by the likes of Baldur's Gate, Fallout or Planescape: Torment. The game adapts Paizo's Pathfinder tabletop system, which is itself based on the rules of the third edition of Dungeons \& Dragons. I chose Pathfinder as my research material, because despite the fantastical setting, the game's graphical user interface abounds with media forms that date from the 13th through 16 th

[32] J. Parikka, What is Media Archeology?, Cambridge - Malden 2012, p. 68.

[33] W. Ernst, op.cit., p 240.

[34] F. Kittler, Discourse Networks..., p. 370.

[35] I am inspired by the general idea behind media archeology, which "sees media cultures as sedimented and layered, a fold of time and materiality where the past might be suddenly discovered anew, and the new technologies grow obsolete increasingly fast". J. Parikka, What is Media Archeology?..., p. 3.

[36] I also suspect that the game is emblematic of the interface design strategy used in many other computer roleplaying games. More thorough research on the topic is needed, though. 
centuries.[36] For example, an image of a portolan chart surrounds the map view of the current in-game location (see il. 1). Mediterranean naval navigators used such portolans from the 13th to 16th centuries to outline the coastlines and chart their travels. [37] An imitation of a spheric astrolabe adorns the screen during the travels on the "overworld" map. As the group explores the land, the device moves slowly, marking the passage of days and nights, which corresponds to the $15^{\text {th }}$ century astrolabes which helped mariners with solar observations and navigation.[38]

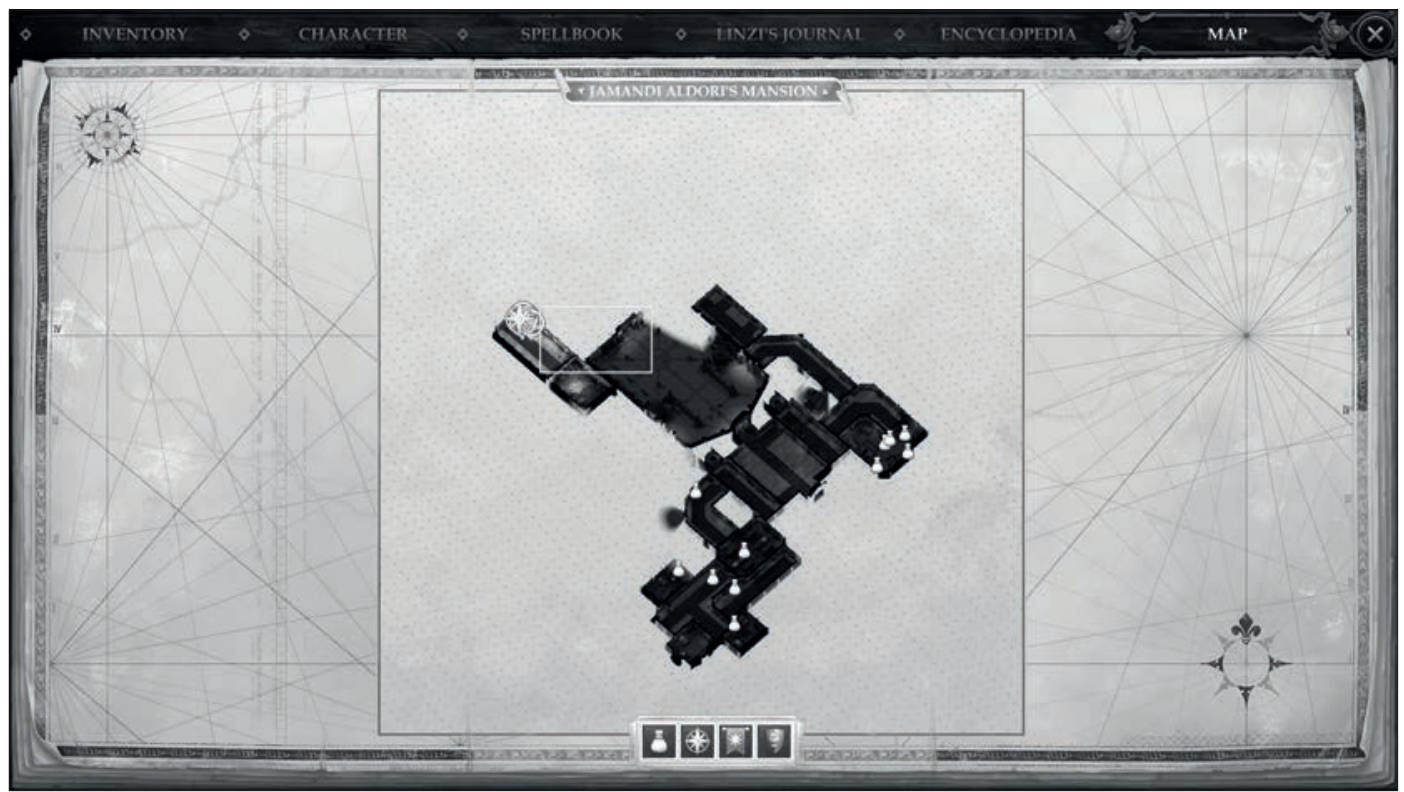

The intermedial strategy in Pathfinder invokes very real, western discourse networks; those that developed at the intersection of Late Medieval period and the Renaissance. Such a choice is not accidental, as the game's fictional setting, too, lies on the edge of cultural change. The interface plays a semantic role, signifying the historical time and the technological context of the cultural practice (exploration) that the game deals with. The players lead a group of adventurers, exploring, colonizing and overseeing the Stolen Lands, a politically-contested province filled with wild nature and magic. To achieve this goal, the party must survive and solve ethical, political and militaristic problems. "Conquer new regions [...], carving your kingdom from the wilderness," [39] the promotional description shouts at the consumers.

Il. 1. The representation of a portolan chart in the map view. Source: Owlcat Games, Pathfinder: Kingmaker, Deep Silver 2018, screenschoot taken by the author
[37] T. Campbell, Portolan charts from the late thirteenth century to 150o, [in:] The History of Cartography, vol. I, eds. J.B. Harley, D. Woodward, Chicago 1987.

[38] E.H. Ash, Navigation techniques and practice in the Renaissance, [in:] The History of Cartography, vol. III, ed. J.B. Harley, D. Woodward, Chicago 1987, pp. 513-518.

[39] See the game's Steam page: <https://store.steampowered.com/app/640820/Pathfinder_Kingmaker_ Enhanced_Plus_Edition/>, accessed: 23.01.2021. 
The game's theme draws on the historical establishment of new relationships between the civilized and wild landscapes which took place in the emerging Renaissance. As Denis Cosgrove explains, the visual discourse of that time had to embody and imagine landscapes that corresponded with the processes of naval exploration, geographical discovery and political occupation of new spaces.[40] The cultural hierarchy "that was widely recognized in the Renaissance" passed "from uncultivated wilderness, through domestic pasture and farmland, to the rational, intellectual spaces of the city." [41] European imagination had to deal with the "domestication of the new, global spatiality that was characterized [...] by the disruption of previously established spatial, ethnographic and conceptual boundaries." [42] Renaissance people were indeed carving their kingdoms from the wilderness.

The virtual spaces of Pathfinder reproduce this configuration, showing the players wild, unexplored landscapes. During gameplay, the users slowly travel from place to place to uncover the fictional region. The software automatically fills out the graphical information missing from the digital maps. The town management mechanics simulate the processes in which the players conquer new areas and mark their territory by establishing and developing centers of commerce: settlements, villages, and towns. Simultaneously, the branching narrative system controls the outcomes of the players' varied decisions. Those decisions are often embedded in the colonial discourse. Who will the players help, the ancient Fey creature of the forest or the lumberjacks who have invaded her home? Will they negotiate a peace between warring tribes of kobolds and mites (integrating them into the growing empire), or will they use the conflict to exterminate both?

The graphical interface design contextualizes the gameplay and the players' actions within the historical moment. By alluding to such technical inventions as portolan charts, cosmographic diagrams, astrolabes, paper notes and documents, landscape paintings, just to name a few, the game affords the players the ability to navigate specific discourse networks and thus to interpret Pathfinder: Kingmaker as a software that is semantically and aesthetically linked with the aforementioned discourse. Yet, these historical allusions work within a game medium that is also involved with computer-based media networks. In consequence, the intermedial structure of Pathfinder relates the game to many historically distant systems of technologies and ideas. What follows now is an analysis that maps this relation.

Material windows

A loading screen is the most recursive image in Pathfinder. When the game data is being loaded into memory, the software displays a wooden table which holds two frames. They imitate the materiality

[40] D. Cosgrove, Geography and Vision. Seeing, Imagining and Representing the World, London - New York 2008, p. 51-54.
[41] Ibidem, p. 52.

[42] Ibidem, p. 53. 
of a hard book cover. The biggest cover encloses a book, opened and ready to look at. The revealed pages of the codex contain another frame, one that resembles the borders of a painting. This final frame encloses a mahogany, rectangular image that shows one of many digital landscapes or interiors explored in the game.

This structure of frames within other frames exhibits a significant logic behind Pathfinder's graphical interface construction. The game depicts the frames as if they were tangible objects. This design principle repeats in all interface windows (il. 2): the stacks of papers are wrinkled and folded, notes and bookmarks protrude from the codex pages, the astrolabe makes characteristic sounds when used, the mouse cursor appears to be made of stone. Such a design principle makes the interface appear as an accurate depiction of material objects from the 13th through 16th centuries. The players are not interacting with the interface, but with the piles of material media and devices.

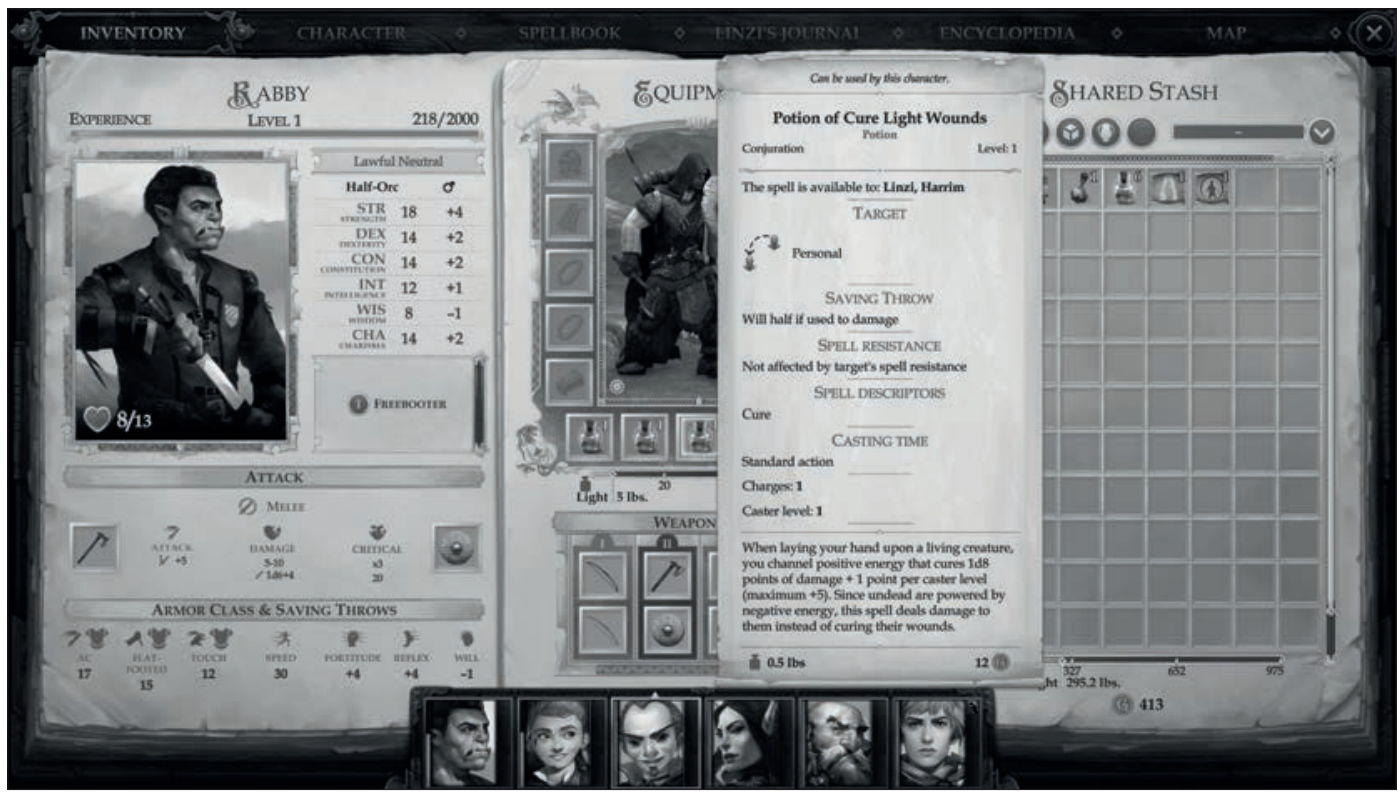

However, the multiplicity and (represented) materiality of the interface are not necessarily used in the game as historically accurate interpretations of the past. They are also products of the contemporary discourses about presenting digital processes and digital data to the users. Despite looking like media from the past, the aesthetics and organization of the game's interface try to solve a very specific computer-related problem: how to allow for quick and intuitive man-machine communication.

The notion of an interface comes from cybernetics. This scientific field has equated men with mechanical systems and established a theoretical framework for reflection about and the development of men-machine communication. Norbert Wiener, probably the most influential cybernetician, provides persuasive examples of correlations

Il. 2. The representation of paper media. Source: Owlcat Games, Pathinder: Kingmaker, Deep Silver 2018, screenschoot taken by the author 
between biological systems (be it a cat[43] or a human brain[44]) and machines, exploring the implications of those findings. He explains that cybernetics are an answer to a new industrial condition in the middle of the $20^{\text {th }}$ Century, during which "the machine" became "a source of control and a source of communication. We communicate with the machine and the machine communicates with us." [45] Thus, designing a viable tools for human-machine communication became a technical and cultural necessity.

The first computer user interfaces used punch-card technologies and were soon replaced by command and text-based modes of communication. It was Ivan Sutherland who reformed those modes into the graphical interfaces used to this day. In his groundbreaking Sketchpad project (a digital program for drawing on a monitor with a light pen), Sutherland invented the interface as a visual device. His technical report reads:

The Sketchpad system makes it possible for a man and a computer to converse rapidly through the medium of line drawings. [...] in the past, we have been writing letters to rather than conferring with our computers. For many types of communication [...] typed statements can prove cumbersome. The Sketchpad system, by eliminating typed statements $[\ldots]$ in favor of line drawings, opens up a new area of man-machine communication.[46]

Sutherland proposes replacing written communication with visualizations of digital processes and human thoughts (the interface works in two directions). In this way, he follows a cybernetic outlook on information as an immaterial entity that can be communicated in any form. As Wiener put it: "The mechanical brain does not secrete though "as the liver does bile,» [...] nor does it put it out in the form of energy, as the muscle puts out its activity. Information is information, not matter or energy." [47]

If information is a pattern that does not depend on its embodiment, then it can be represented by mathematical operations, [48] and those operations can be visualized on the screen for users. This way of thinking was crucial for the development of contemporary interface designs and therefore can help us understand the intermedial structure in Pathfinder. The notion that information and physicality are two separate categories was widespread in the information-focused theories of such cyberneticians as John von Neumann, Claude Shannon or

[43] N. Wiener, The Human Use of Human Beings. Cybernetics and Society, London 1989, p. 22.

[44] Ibidem, p. 17.

[45] Idem, Men, machines and the world about, [in:] The New Media Reader, eds. N. Wardrip-Fruin, N. Montfort, Cambridge - London 2003, p. 71. [46] I.E. Sutherland, Sketchpad: A man-machine graphical communication system, technical report, University of Cambridge Computer Laboratory, 2003,
<https://www.cl.cam.ac.uk/techreports/UCAM-CLTR-574.pdf $>$, accessed: 23.01.2021.

[47] N. Wiener, Cybernetics or Control and Communication in the Animal and the Machine, Cambridge 1985, p. 132.

[48] See: C. Shannon, A mathematical theory of communication, "The Bell System Technical Journal” 1948, vol. 27. 
Warren Sturgis McCulloch,[49] and later spread to popular culture and early stages of media-orientated research. Because digital media were strongly associated with information processing, they were quickly outlined as almost immaterial entities with their "virtual" spaces and forms. In consequence, the discourse of "new" media differentiated digital computers from the homogenic age of the past, in which the materiality of media reigned supreme. Manovich's foundational text on digital media provides an example of such a simplification. When writing about computer-generated graphics, Manovich argues: "if Medieval masters left after themselves the material wonders of stone and glass [...], today our craftsmen leave just the pixel sets to be projected on movie theater screens or played on computer monitors. These are immaterial cathedrals made of light [...]," [50] simply ignoring for a moment that even photons of light are part of the physical world.

Manovich's description becomes especially striking in the context of Pathfinder, because the game tries to balance its "immaterial" digitality with the representation of the material wonders of Late Medieval and Early Renaissance media. Comparably to Manovich, the game's interface portrays this pre-digital discourse network as an exceptionally material phenomenon. The overabundance of visual signifiers marking the interface as a corporal entity is overwhelming. Some of the windows are structured with layers upon layers of paper, as if almost the whole interface was made out of books, scrolls and paper sheets. The central position of paper media not only corresponds with their significance in the represented discourse network, it also constructs the interface as an embodiment of (immaterial) information. N. Katherine Hayles explains that when approached from the perspective of information theory, "the book is a form of information transmission and storage" that "incorporates its encodings in a durable material substrate."[51] Once produced, books fuse the information and its embodiment, so they cannot be separated.[52]

From this perspective, the paper-like construction of the interface can be seen as irrefutable proof of its materiality. Pathfinder's graphical design depicts the discourse network in question as a material web of things, a system on the brink of disorder (all those heaps of paper could get mixed up so easily), a system in which information is spread through distinct and separate media artifacts (do the characters really need to carry all these objects with them?). This corporeal excessiveness negotiates the (presumed) lost materiality of digital media.[53] As inter-

[49] N. Katherine Hayles provides a detailed history of the cybernetic distinction between information and materiality: N.K. Hayles, How We Became Posthuman. Virtual Bodies in Cybernetics, Literature, and Informatics, Chicago - London 1999.

[50] L. Manovich, Software Takes Command, p. 201.

[51] N.K. Hayles, op.cit. p. 28.

[52] Ibidem, p. 29.
[53] Those familiar with the rule books published under the tabletop Pathfinder brand may notice that the books also evoke many media from the past. There is no denying the fact that the Pathfinder: Kingmaker's interface also corresponds with the tabletop products. Yet, a short examination of the D\&D rulebooks preceding Pathfinder (the tabletop game) shows a more complicated story. Up until the second edition 
face scholar Angela Zhou puts it, "graphical user interface is a manifest artifact [...]. It exists more richly and haptically to compensate for the immateriality of the digital [...]."[54]

This discourse of compensation can be traced back to Ivan Sutherland, who used a cybernetic idea to create a skeuomorphic graphical interface. His Sketchpad represents digital operations with geometrical shapes that can be effortlessly drawn, resized, erased or multiplied on the screen. It is not a coincidence that he choose a very physical technique. Drawing, a very corporal practice, brings digital operations closer to the users. They can imagine computer work as something that pertains to their previous, materially-embedded media experiences. Identically, Pathfinder's interface - a not-so-distant relative of Sketchpad - explains its game mechanics with the aesthetics and functions of the chosen media devices. Both interfaces recreate certain media as visual metaphors that make the computer processes approachable even by the most inexperienced users. Sketchpad and the game share the assumption that the only metaphors the users can comprehend are material metaphors.

\section{Threshold devices}

Hayles observes that in cybernetic discourse, skeuomorphs "acted as threshold devices" that connected different "conceptual constellations." [55] In other words, skeuomorphism is based on the fact that it is much easier to understand new devices through the lens of a familiar one. The interface designers use skeuomorphism to filter or hide the innerworkings of the computer, so users do not have to worry about them and can effortlessly interact with the software.

In the case of Pathfinder, the intermediality of the interface delays the users' realization that what they really experience is not a fantasy universe, but a complicated calculation program. In his research, Kubiński argues that "extra-diegetic" interfaces can easily break the immersion of the players. He notes that game designers try to counter this effect by creating interfaces that imitate objects associated with the game's diegesis. [56] Pathfinder's interface follows such a strategy, because the success of its narrative rests on the players' immersion in the fictional world. The software refers the users to the discourse network of the $13^{\text {th }}-16^{\text {th }}$ centuries, so they can experience the game through the recognizable frames that correspond with its diegesis, themes and rules.

of $\mathrm{AD} \& \mathrm{D}$, the rulebooks were rather plain looking, with very clean, often minimal designs. The elaborate graphical layouts were introduced in the third edition of D\&D, after the brand was incorporated into Wizards of the Coast's catalog. Pathfinder's rules are an offshoot of this edition. The third edition, published in 2000, followed a successful series of isometric, real-time games based on D\&D: Baldur's Gate and its sequel, Icewind Dale, Planescape Torment. The layout of $\mathrm{D} \& \mathrm{D}$ tabletop products seems to be, at least partially, a direct response to the design trends in the digital games.

[54] A. Zhou, Cybernetics and human-computer interaction: Case studies of modern interface design, in 2014 IEEE Conference on Norbert Wiener in the 21st Century (21CW), ed. M. Gibbs, Boston 2014, DOI: 10.1109/NORBERT.2014.6893925, p. 2.

[55] N.K. Hayles, op.cit., p. 17.

[56] P. Kubiński, op.cit., pp. 182-187. 
The narrative and the game mechanics (traveling, fighting, town building) become linked with the represented media, and in consequence, they all merge into a coherent product.

Pathfinder heavily implies that players should treat the interface as a set of windows, thanks to which they can access and experience the narrative game. This becomes especially evident on the loading screen (see il. 3), which literally displays a system of overlapping windows: a book holds a painting frame on its pages. If interpreted in the context of the represented discourse network, a landscape framed on a book page appears to reference an older window metaphor, one that was used by the perspective painters in the Renaissance. There is a strong similarity between the discursiveness of visual interfaces and perspective paintings. Both media forms express mathematical logic with the techniques of visual representation. After all, linear perspective represents a three dimensional space on a two-dimensional canvas with a precise use of mathematics and optical properties.

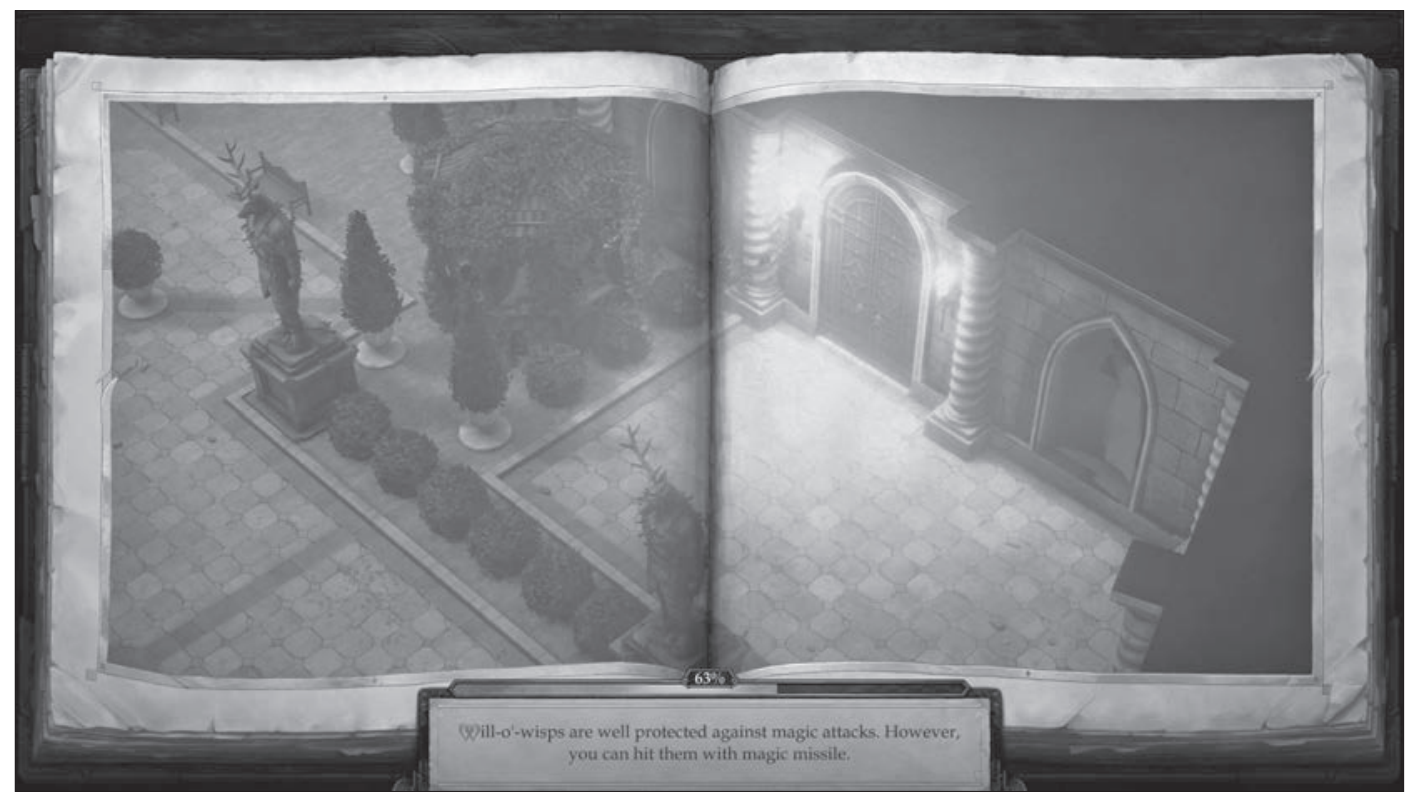

The technique started with Filippo Brunelleschi who, when inspired by antique writings on optics, made a visual experiment. $\mathrm{He}$ created a perspective painting of Florentine Baptistery with a small hole inside and provided the viewers with a hand mirror punctuated with identical hole. The viewers were supposed to hold the painting outwards, look through it and align the mirror so the two holes remained parallel, and finally observe the reflection of the painting. As a result, the device produced an illusion of depth.[57] The set of

[57] R. Lancia, Narrating built heritage by its own storytelling, "The International Journal of Virtu- al Reality" 2008, vol. 7, no. 2, p. 81; S. Edgerton, Brunelleschi's mirror, Alberti's window, and Galileo's 
tangible materials (the painting and the mirror) materially framed the viewing experience of the spectators, dictating the position and movement of the eye, so the effect of "looking through" at a represented space could be achieved. Following Brunelleschi, Leon Battista Alberti simplified the method and compared perspective paintings as windows: "First I trace as large a quadrangle as I wish, with right angles, on the surface to be painted; in this place, it certainly functions for me as an open window through which the historia is observed, and there I determine how big I want men in the painting to be [...]." [58] Alberti's window does not open onto reality, but functions as a transparent display that shows a representation of narrative space ("historia").[59] This painting technique became important for many artists.

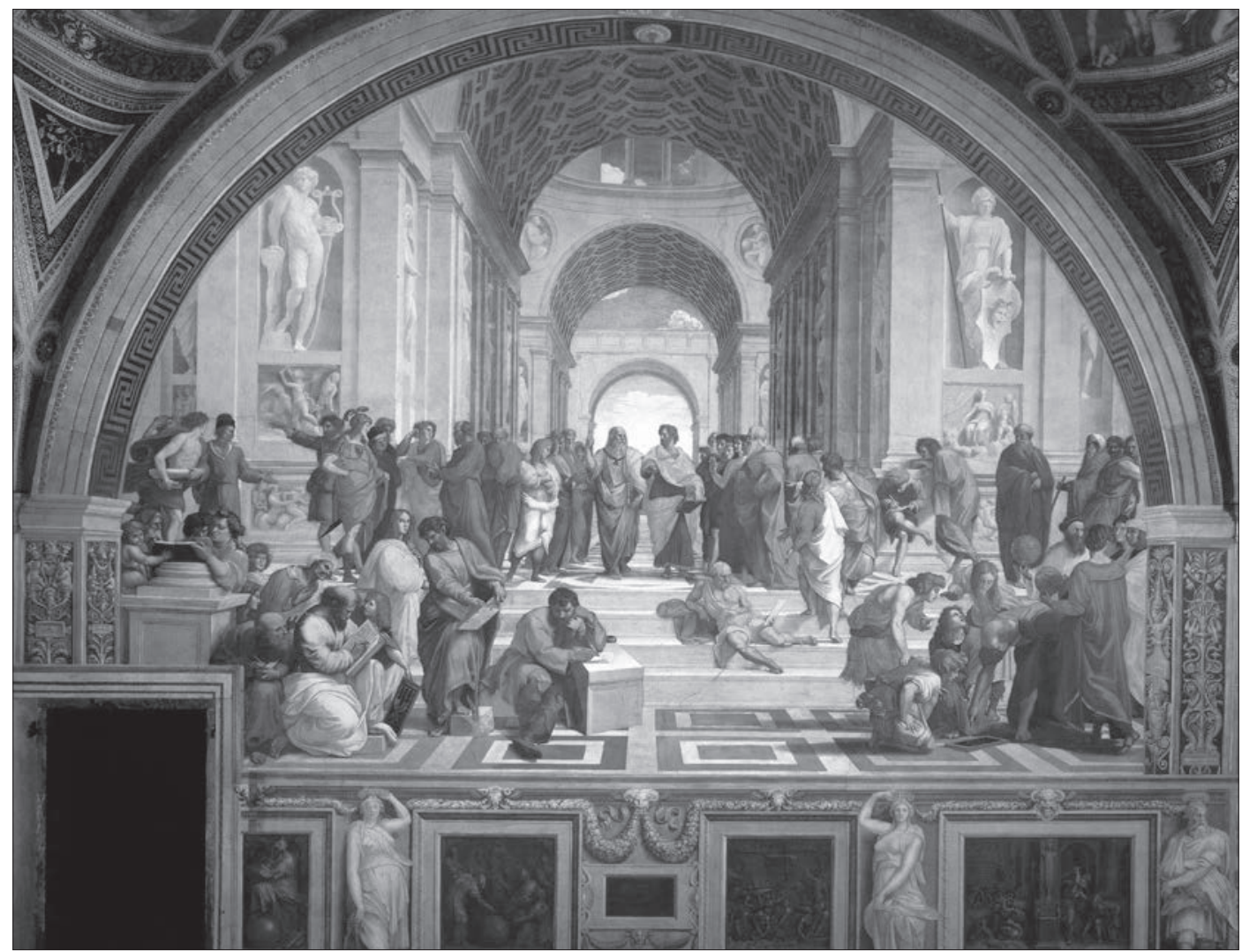

Il. 4. Raffaello Sanzio da Urbino, The School of Athens. Source: wikimedia (public domain)

'perspective tube', "Historia Ciencias Saude-manguinhos" 2006, vol. 13, p. 159, DOI 10.1590/So10459702006000500010.

[58] L.B. Alberti, On Painting. A new translation and critical edition, transl. and ed. R Sinisgalli, New York 2011, p. 19.
For example, a fresco located in the Apostolic Palace in the Vatican, The School of Athens by Raphael, incorporates such a transparent opening (il. 4). The mural encloses the depicted scene with
[59] A. Friedberg, Wirtualne okno. Od Albertiego do Microsoftu, transl. A. Rejniak-Majewska, M. Pabiś-Orzeszyna, Warszawa 2012, pp. 69-70, 75. 
an architectural arch that seems to be a natural part of the room. The arch appears to be an extension of the walls, as if it was a tangible and material portal through which the viewers can step into the painting. Of course, in reality the arch is a painting, an integral part of the fresco. It is a portal for seeing (the fictional space- and the events that take place in it). And thus, in addition to enclosing a narrative space, the frame also encloses the viewers. Only when they stand in a specific position before the painting and focus on it can they fully experience the illusion of "looking through" the frame.

Pathfinder's interface metaphorically alludes to Brunelleschi's experiment and Alberti's window (compare il. 3 with il. 4). The game a,so recreates a set of tangible materials (e.g. the wooden desk, the book and the painting frame) that work as a see-through devices, promising an illusion of non-mediated experience, which plays a key role in the roleplaying genre. Those frames form the user's expectations, suggesting to them that they are engrossed and participating subjects who look or cross through the interface at/into a narrative space.

Still, the contexts in which the linear perspective and the graphical interface developed are quite different. The linear perspective was conceived as a method that brings the narrative space closer to its audience.[60] That is why, in his instruction, Alberti stressed the correct positions of human figures on the painting. If the painter follows certain rules, those figures will appear to be standing right before the viewers' eyes. Linear perspective presents narrative space from a human point of view. Pathfinder abandons this method and visually displays its world with an isometric projection. The players observe the characters from above, at a 30 degree angle. The point of view is not fixed in place. The world is not brought closer to the users; it is made distant.

Isometry was popularized in Europe by William Farish.[61] He had greatly facilitated the western understanding and usages of isometCommand and work ric projection with his pamphlet On Isometrical Perspective. In the text, Farish links isometrical projection with engineering, because it allows precise technical drawings, which, unlike linear perspective, do not distort the depicted objects. [62] The western history of isometry shows that since then, it has been interpreted as a technical and reliable way of seeing. [63] That is why it is mainly used in manufacturing, architectural planning, and map making.

When a narrative game like Pathfinder employs isometric perspective, the players' experience becomes so much different from the

[60] S. Edgerton, op.cit., p. 157.

[61] Isometrical paintings originated in China, but Europeans adapted them to industrial needs and since then have largely ignored their source. J. Krikke, Axonometry: a matter of perspective, "IEEE Computer Graphics and Applications" 200o, vol. 20, no 4, p. 8, DOI: $10.1109 / 38.851742$.
[62] Ibidem, pp. 8-9.

[63] See: F. Cocozza, Axonometry: The grip of thought on space - a short survey on the relation between the act of planning and a visionary visualization technique, "Proceedings" 2017, vol. 1, no. 9. 
experience founded on Alberti's windows. The isometric image places its viewers, as Adam Jasper puts it, an "infinite distance away", and thus allows them to inspect the depicted space "with infinite clarity." [64] While the game pretends (mainly through its diegetic stylization of the interface) to immerse the players in the characters of their choosing, it actually detaches the players from the represented world. Isometric representations of space are designed as maps of rational thought.[65] They must be read as abstractions, not illusions of being near or in the narrative space.

Why would a roleplaying game use such method of representation? Because at its core, Pathfinder is a management software. The popularity of isometrical drawings in the 19th century resulted from the fact that factory workers could easily read them and learn the required montage procedures. In the same way that isometrical projection constitutes efficient workers, the graphical user interface coerces the players to reenact different techniques associated with bureaucratic and military work. The game users issue commands to their subordinates (the adventuring party). They manage numerical data by choosing the adventuring gear in the inventory display, and outlining the battle strategy. The battle calculations displayed during the gameplay provide intricate data about the party's and enemies' performance in the battle. The players administer human resources by deciding on the party's composition and how to develop each character. The detailed character screens allow the players to compare numerical data about the abilities of the protagonist and her or his companions. Finally, the top-down views of the fictional world imagines the space as a series of battlefields, overseen and managed by the players on the battlefield.

Isometric view and user interfaces express a cultural need for meticulous control. The discourse network of control devices exploded at the beginning of $19^{\text {th }}$ century, when pre-industrial media could no longer keep up with the rising amounts of processed energy, material goods and information. This "control revolution", as James Beniger names it, took place between the 1840 s and the 1920s, giving rise to systems that expanded human capacity to process data and rationalize complicated streams of information.[66] The skeuomorphic interface design and isometrical view are then related practices which efficiently streamline and communicate complex data, so they can be worked on by people with no technical background.

The cybernetic discourse, on which the very idea of human-computer interface was based, was brought about by the control revolution. [67] Cybernetic field was essentially a science of control that reshaped chosen problems (including the notion of communication) into prob-

[64] A. Jesper, God's eye view, [in:] This Thing Called Theory, eds. T. Stoppani, G. Ponzo, G. Themistokleous, London 2016, e-book. [65] F. Cocozza, op.cit., p. 10.
[66] J.R. Beniger, The Control Revolution. Technological and economical origins of the information society, Cambridge - London 1986, pp. 9, 15, 426-427.

[67] Ibidem, p. 407. 
lems of command and regulation. The Greek word kubernètēs connotes a boat steersman, a nautical captain, a leader or a governor.[68] The cybernetic interface frames the players as controlling subjects, presenting them with forms through with they can govern information and work effectively.

The very first interface the players see, the game's title screen (il. 5), contextualizes itself in accordance with such logic. The camera approaches a dimly lit table. As the camera gets closer, it reveals a plethora of material documents (a map, a letter, sheets of paper, a book), all of which are later represented on other interface screens. This image, of course, signals the game's relation with the $13^{\text {th }}-16^{\text {th }}$ century discourse network. But the intermediality at play here does more than that; it also recreates the computer as a physical-office metaphor, developed and put into practice at Xerox's Palo Alto Research Center and Sandford Research Institute.

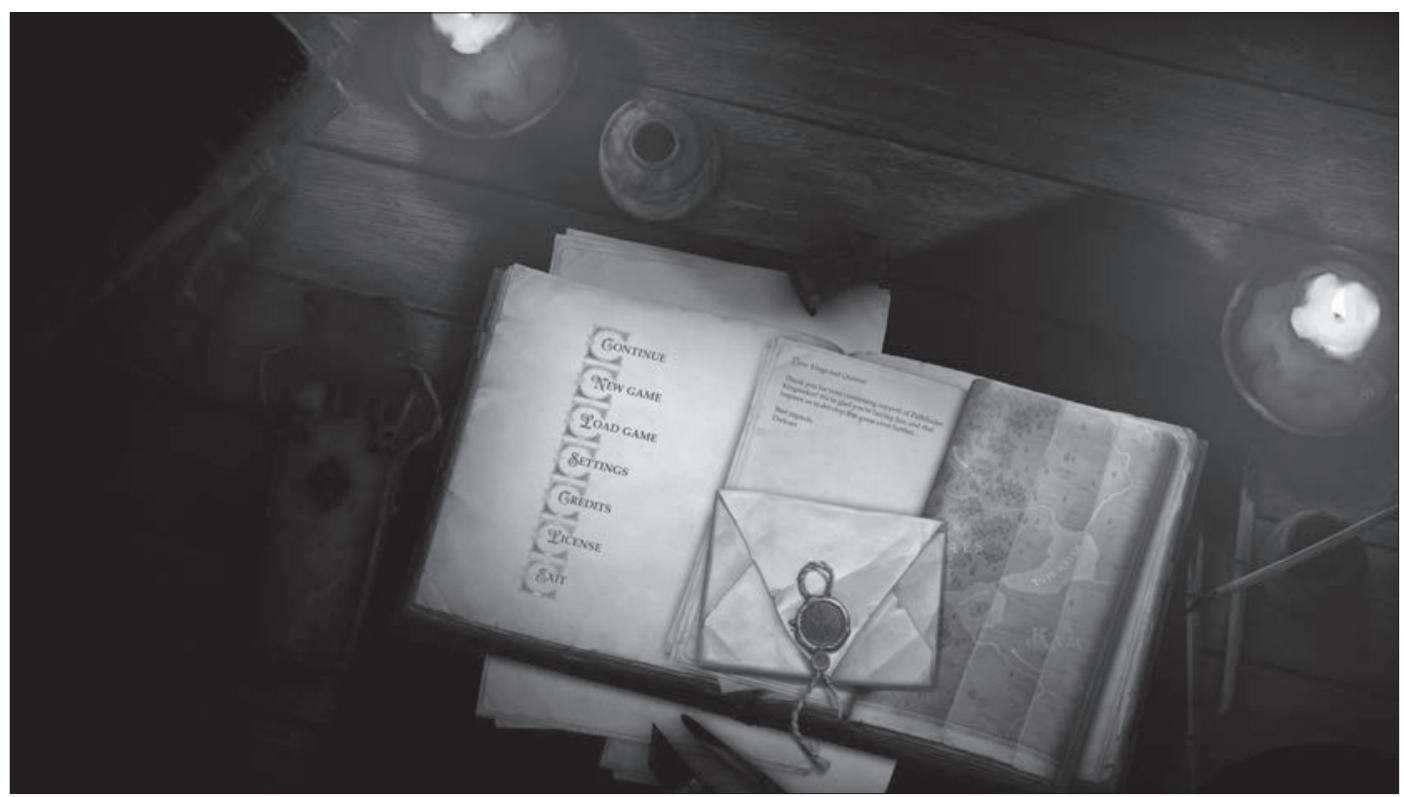

Those institutions designed and implemented the first commercial incarnation of a graphical user interface in Xerox Alto (1973, an experimental model) and Xerox Star (1981, mass produced model) machines. Both computers employed an interface that was imagined as a working station; a space "organized like an "electronic desktop»" [69] (see il. 6). Some of the Xerox employees who worked on the Star system describe their computer as follows:

Every user's initial view of Star is the "Desktop," which resembles the top of an office desk, together with surrounding furniture and equipment. It
Il. 5. The digital representation of a "pre-digital desktop". Source: Owlcat Games, Pathfinder: Kingmaker, Deep Silver 2018, screenschoot taken by the author

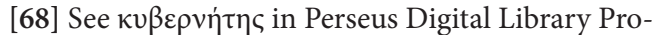
ject, <www.perseus.tufts.edu $>$, accessed: 23.01.2020. [69] See Xerox 8010 speaks your language (brochure), in DigiBarn computer museum, <https://www. digibarn.com/friends/curbow/star/2/index.html>, accessed: 23.01.2020. 
Il. 6. Xerox Star. Source: DigiBarn Computer Museum represents your working environment - where your current projects and accessible resources reside. On the screen are displayed pictures of familiar office objects, such as documents, folders, file drawers, in- baskets, and out-baskets.[70]

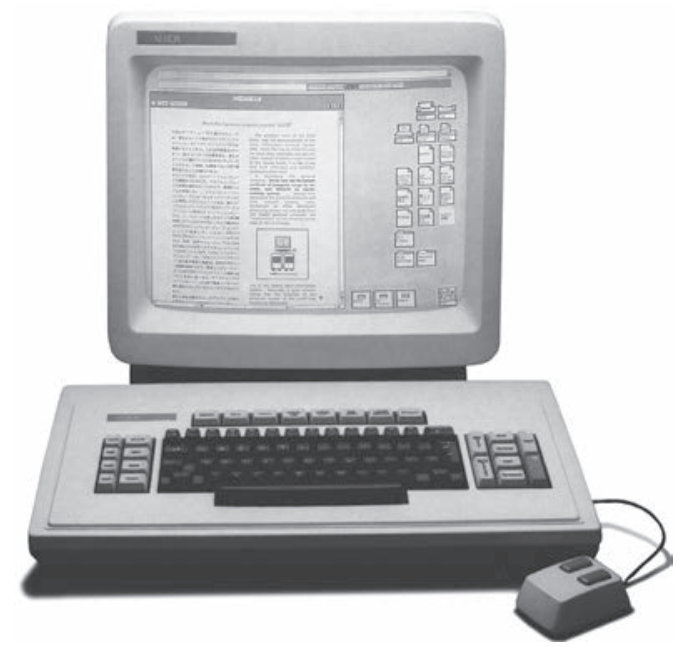

The game's title screen replicates this structure, the only difference being that the game represents familiar objects from a different time period. Even the (wooden) desktop is present in the background. The title screen displays a working station as it would look if the same work-related discourses existed in the $15^{\text {th }}$ century.

The engineers behind Xerox Star developed its interface as a continuation of a media network, which includes desks, printers, files and other machines used in the office. Similarly to Sutherland, they too tried to balance the presumed material difference between digital and tangible media: "the icons [...] are visible, concrete embodiments of the corresponding physical objects. Star users are encouraged to think of the objects on the Desktop in physical terms." [71]

Alberti's metaphor remained valid for the programmers of Star, but one of the designers, Alan Key, refashioned it into "the principal mechanism for displaying and manipulating information." [72] The computer utilizes its windows in the similar way workers utilize papers and documents on their desks. Windows behave like pages: they can be easily moved and layered on top of each other.[73] This idea explains Pathfinder's preoccupation with heaps of overlapping paper in the interface. Its design replicates both the $13^{\text {th }}-16^{\text {th }}$ century discourse network and the principles popularized by Kay. The School of Athens and the Xerox Star's operating system are also related. The first one
[70] D.C. Smith, C. Irby et al., Designing the star user interface, "Human-Computer Interaction" May 1990, $<$ https://tech-insider.org/star/research/acrobat/8204. pdf>, accessed: 23.01.2020.
[71] Ibidem, p. 256.

[72] Ibidem.

[73] Ibidem. 
extends the room into the picture, the second one expands the office onto the computer screen. Still, while the computer windows retain Alberti's idea of looking through a medium at something, they are experienced as layered and navigable objects,[74] or to be more precise, elements of a contemporary office space. Pathfinder's narrative space is, in fact, an office environment, and thus what the players look at and experience is an intermedially-constructed administration desk. The game's correspondence with the discourse network of office devices is quite simple. The office workers are required to move between different technical devices (printers, document folders, staplers, phones...) and operate them to carry out specific tasks, remember their location and (if needed) cataloging logics (the files in the folders), while at the same time interpreting and directing a constant transmission of information that comes in and out of those devices. The players playing Pathfinder: Kingmaker are involved in a similar relationship with the media devices represented in the graphical user interface. The interface refashions the users into subjects that are preoccupied with the control of media devices. The players, too, need to quickly move between different interface tabs, and learn the role of each screen and interactive buttons, so they can operate the systems as precisely as possible. For example, they must know how to display and segregate the overflow of items collected during the exploration. They should master the ability to access and read data about the party's statistics, abilities and inventory, so they can successfully modify them when needed. They must commit to the act of switching between isometric and map views of the explored space, so they do not get lost while traveling.

As I have already mentioned at the beginning, the discourses of exploration and discovery contribute to the game's themes of colonization. Yet, the crucial navigation practice that the players participate in has more to do with movement through the office media environment than with the exploration of fantastical landscapes. The users are, in fact, experiencing an excess of documents and devices that help with the supervision of different tasks. Each gameplay session consists of multiply excursions through the Late Medieval and Early Renaissance media pictured in the interface.

The function of players/kubernètēs blends navigation techniques with technical control. The graphical user interfaces were always designed as spaces for movement. After inventing his interface, Sutherland proclaimed that "the properties of a computer drawing are entirely different from a paper drawing [...] primarily because of the ability to move drawing parts around [...]." [75] Manovich explains this tendency by comparing computer users with characters from the Tron movie. They zap "through the immaterial space defined by lines of light." [76] 
Aren not those lines the very same lines used by Sutherland to compose geometrical shapes on a computer screen? I think they are. I agree with Manovich when he maintains that "the idea of navigable space lies at the very origins of computer era. The steersman navigating the ship and the missile traversing space on its way to the target have given rise to a whole number of new figures [...]." [77]

One of those figures is the player exploring an interface environment. I do not interpret the intermedia relations in Pathfinder: Kingmaker as a case of discoursive continuities, raptures or paradoxes. Those relations build a historically complex device. During the gameplay, the users not only navigate representations of the chosen media, but also explore the discourse networks associated with them. Regardless if they aware of the fact or not, the players can experience those networks as interlaced layers of meanings and practices.

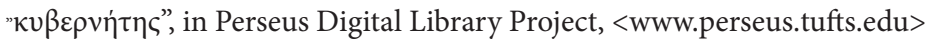

Alberti L.B., On Painting. A new translation and critical edition, transl. and ed. R. Sinisgalli, New York 2011

Anderson C.U., S.B. Pold, Interface Criticism, Aarhus N 2011

Ash E.H., Navigation techniques and practice in the Renaissance, [in:] The History of Cartography, vol. III, ed. J.B. Harley, D. Woodward, Chicago 1987

Beniger J.R., The Control Revolution. Technological and economical origins of the information society, Cambridge - London 1986

Campbell T., Portolan charts from the late thirteenth century to 1500, [in:] The History of Cartography, vol. I, eds. J.B. Harley, D. Woodward, Chicago 1987

Celiński P., Interfejsy. Cyfrowe technologie w komunikowaniu, Wrocław 2010

Cocozza F., Axonometry: The grip of thought on space - a short survey on the relation between the act of planning and a visionary visualization technique, "Proceedings" 2017, vol. 1, no. 9, <https://doi.org/10.3390/proceedings1090884>

Cosgrove D., Geography and Vision. Seeing, imagining and representing the world, London - New York 2008

Edgerton S., Brunelleschi's mirror, Alberti's window, and Galileo's 'perspective tube', "Historia Ciencias Saude-manguinhos" 2006, vol. 13, p. 159, DOI 10.1590/ S0104-59702006000500010

Ensslin A., Literary Gaming, Cambridge - London 2004

Ernst W., Media Archaeography. Method and machine versus history and narrative of media, [in:] Media Archeology. Approaches, applications, and implications, eds. E. Huhtamo, J. Parikka, Berkeley - Los Angeles - London 2011

Foucault M., The Archeology of Knowledge, transl. A.M. Sheridan Smith, New York 1972

Friedberg A., Wirtualne okno. Od Albertiego do Microsoftu, transl. A. Rejniak-Majewska, M. Pabiś-Orzeszyna, Warszawa 2012

Gaudreault A., Marion, P., The Cinema as a model for the genealogy of media, "Convergence" 2002, vol. 8, no. 4. DOI:10.1177/135485650200800402

Girina I., Video game mise-en-scene remediation of cinematic codes in video games, [in:] Interactive Storytelling. ICIDS 2013. Lecture Notes in Computer Science, eds. H. Koenitz, T.I. Sezen, G. Ferri, Cham 2013

[77] Ibidem, p. 251. 
Groppo P., Narrative ludology: intermediality in adventure games, "Em Tese" 2012, vol. 18, no. 3, DOI: 18. 96. 10.17851/1982-0739.18.3.96-108

Hayles N.K., How We Became Posthuman. Virtual bodies in cybernetics, literature, and informatics, Chicago - London 1999

Huhtamo E., Dismantling the fairy engine. Media archeology as topos study, [in:] Media Archeology. Approaches, Applications, and Implications, Berkeley, Calif., 2011

Interactive Storytelling. ICIDS 2013. Lecture Notes in Computer Science, ed. H. Koenitz, T.I. Sezen, G. Ferri, Cham 2013, <https://doi.org/10.1007/978-3-31902756-2_5>

Intermediality and Media Change, eds. J. Herkman, T. Hujanen, P. Oinonen, Tampere 2012

Järvinen A., Gran Stylissimo: The audiovisual elements and styles in computer and video games, [in:] Proceedings of Computer Games and Digital Cultures Conference, ed. F. Mäyrä. Tampere 2002

Jesper A., God's eye view, [in:] This Thing Called Theory, eds. T. Stoppani, G. Ponzo, G. Themistokleous, London 2016, e-book

Jørgensen I.K.H., Media and games: an intermedial framework, in FDG '18: Proceedings of the 13th International Conference on the Foundations of Digital Game, eds. S. Dahlskog, S. Deterding, J. Font, Malmö 2018, <https://doi. org/10.1145/3235765.3235794>

King G., Krzywinska T., ScreenPlay. Cinema/videogames/interfaces, London - New York 2002

Kittler F., Discourse Networks 1800/1900, transl. M. Metteer, C. Cullens, Stanford 1990

Kittler F., Gramophone, Film, Typewriter, transl. G. Winthrop-Young, M. Wutz, Stanford 1999, xli

Krikke J., Axonometry: a matter of perspective, "IEEE Computer Graphics and Applications" 2000, vol. 20, no. 4, DOI: 10.1109/38.851742

Kubiński P., Gry wideo. Zarys poetyki, Kraków 2016

Lancia R., Narrating built heritage by its own storytelling, “The International Journal of Virtual Reality" 2008, vol. 7, no. 2

Lippitz A., Lost in the static?: Comics in video games, [in:] Intermedia Games Games Inter Media: Video Games and Intermediality, eds. M. Fuchs, J. Thoss. New York 2019

Manovich L., Software Takes Command, New York - London 2013

Manovich L., The Language of New Media, Cambridge - London 2011

Mueller J., Intermediality, Quo Vadis?: A brief inventory and a road map for six central future research axes, "International Journal of Semiotics and Visual Rhetoric" 2019, vol. 3, DOI: 10.4018/IJSVR.2019070102

Ndaliains A., Neo-Baroque Aesthetics and Contemporary Entertainment, Cambridge - London 2004

Neitzel B., Performing games: intermediality and videogames, [in:] Handbook of Intermediality, ed. G. Rippl, Berlin - Boston 2015, e-book

Owlcat Games, Pathfinder: Kingmaker, Deep Silver, PC game, 2018

Parikka J., Insect Media. An archaeology of animals and technology, Minneapolis, London 2010

Parikka J., What is Media Archeology?, Cambridge 2012

Rajewsky I.O., Intermediality, intertextuality, and remediation: a literary perspective on intermediality, "Intermédialités" 2005, vol. 6, no. 6, DOI: 10.7202/1005505ar

Raupach T., Towards an analysis of strategies of authenticity production in World War II first-person shooter games, [in:] Early Modernity and Video Games, eds. T. Winnerling, F. Kerschbaumer, Newcastle 2014

Schröter J., Discourses and models of intermediality, "CLCWeb: Comparative Literature and Culture" 2011, vol. 13. DOI: 10.7771/1481-4374.1790 
Shannon C., A mathematical theory of communication, "The Bell System Technical Journal" 1948, vol. 27

Siegert B., Cultural Techniques: Grids, Filters, Doors, and Other Articulations of the Real, transl. G. Winthrop-Young, New York 2015

Smith D.C., C. Irby et al., Designing the star user interface, "Human-Computer Interaction" May 1990, <https://tech-insider.org/star/research/acrobat/8204. pdf>, accessed: 23.01.2020

Sutherland I.E., Sketchpad: A man-machine graphical communication system, technical report, University of Cambridge Computer Laboratory, 2003, <https:// www.cl.cam.ac.uk/techreports/UCAM-CL-TR-574.pdf>, accessed: 23.01.2021

The Xerox 8010 speaks your language (brochure), in DigiBarn computer museum, <https://www.digibarn.com/friends/curbow/star/2/index.html>, accessed: 23.01.2020

Wellbery D.E., Foreword, [in:] F. Kittler, Discourse Networks 1800/1900, transl. M. Metteer, C. Cullens, Stanford 1990

Wiener N., Cybernetics or Control and Communication in the Animal and the Machine, Cambridge 1985

Wiener N., Men, machines and the world about, [in:] The New Media Reader, ed. N. Wardrip-Fruin, N. Montfort, Cambridge - London 2003

Wiener N., The Human Use of Human Beings. Cybernetics and Society, London 1989

Zhou A., Cybernetics and human-computer interaction: Case studies of modern interface design, in 2014 IEEE Conference on Norbert Wiener in the 21st Century (21CW), ed. M. Gibbs, Boston 2014, DOI: 10.1109/NORBERT.2014.6893925

Zielinski S., Deep Time of the Media: Toward an archaeology of hearing and seeing by technical means, trans. G. Custance, Cambridge, London 2006 